\title{
Influence of the Year and HMW Glutenin Subunits on End-use Quality Predictors of Bread Wheat Waxy Lines
}

\author{
R. LUCAS, M. RODRÍGUEZ-QUIJANO*, J.F. VÁZQUEZ and J.M. CARRILLO \\ Unidad de Genética, Departamento de Biotecnología. Universidad Politécnica, Ciudad Universitaria s/n, \\ 28040 Madrid, Spain
}

\begin{abstract}
The effects of environment and the high inolecular weight glutenins on soine quality properties (sedimentation volume, \% protein content, and starch pasting viscosity) of bread wheat Inutant waxy lines were evaluated. Thirty eight $100 \%$ anylose-free $\mathrm{F}_{2}$ derived $\mathbf{F}_{6}$ and $\mathrm{F}_{7}$ lines were used. The results indicated that the environment did not influence sedimentation volume, inixograph parameters and starch viscosity parameters of waxy flour. Variation in the \% protein content was determined mainly by the environment. The sedimentation volume and the inixograph peak development time were influenced by the variation at over expression of $\mathrm{Bx} 7$ and the mixograph peak development time was influenced by the Glu-D1 locus. One starch viscosity paraneter, time to peak viscosity, was influenced by variation at the Ghu-Al locus. This parameter is significantly lower in the waxy lines than the parent line, which shows the influence of the waxy loci. No significant comelation was observed for sedimentation volume. mixograph parameters, protein content and viscosity parameters of waxy lines.
\end{abstract}

Keywords: Triticum aestivum; bread wheat quality; starch viscosity

\section{Introduction}

In the majority of bread wheat varieties (Triticum aestivum L. genome AABBDD), the endosperm starch is composed of the polysaccharides amylose and amylopectin in the approximate ratio of 25:75\% (Preiss 1991). Amylose has a linear structure while amylopectin is branched. Amylose is synthesized mainly through the action of the enzyme "granule-bound starch synthase"'(GBSS) (Echt and Schwartz 1981) which is coded by the Waxy loci $(W x)$. These loci are located on the short arms of chromosomes 7A and 7D and on the long arm of chromosome $4 \mathrm{~A}$, as a result of translocation from chromosome 7B (Naranjo et al. 1987). Their products are three waxy isoenzymes which may be separated by electrophoresis (Nakamura et al. 1993).

Some wheat varieties have been found to have low amylose content and it has been observed from electrophoretic gels that one or more of these GBSS isoenzymes are not expressed. These varieties are referred to as "partial waxy mutants". It has also been observed that there is a relationship between the physico-chemical properties of starch from 
bread wheat and their content of amylose. In the case of wheats whose amylose content is close to $0 \%$ (is named waxy mutant), it has been observed that their starch viscosity properties differ from those of normal wheat as do those of the different "partially waxy mutants" (Hayakawa et al. 1997). Kiribuchi-Otobe et al. (1997) and Kim et al. (2003) found that, in waxy wheat lines, the peak viscosity of starch measured by the Rapid Visco Analyser (RVA) occurred at earlier times than non-waxy wheats and at a temperature lower by between 10 and $15^{\circ} \mathrm{C}$ than normal or partially waxy wheats. Kiribuchi-Otobe et al. (1997) and Kim et al. (2003) found that waxy lines had a peak viscosity higher than non-waxy, while the peak viscosity of waxy lines analyzed by Hayakawa et al. (1997), Yasui et al. (1999) and Sasaki et al. (2000) had lower values than non-waxy. Bettge et al. (2000) reported that starch granules of waxy wheat were more susceptible to physical damage than those that contain amylose. Yoo and Jane (2002) and Kim et al. (2003) found that the crystallinity of waxy bread wheats was significantly greater than that of normal lines. This characteristic has also been observed in waxy lines of other cereal species such as barley (Song and Jane 2000) and potato (McPherson and Jane 1999). Also the lack of amylose produces a reduction of staling in bread (Nakamura et al. 1995).

In bread wheat, in addition to the type of starch that a variety has protein quality characteristics such as the baking strength and protein content are also of great interest to the flour and baking industry. The baking strength or gluten strength depends to a large extent on the genetic composition of the variety and the specific composition of the endosperm protein, particularly the insoluble fraction of glutenin of high molecular weight (Payne et al. 1979). These proteins, in bread wheat, are controlled by complex loci located on the long arms of group 1 chromosomes 1A, 1B and 1D (Payne et al. 1982; Shewry et al. 1992). The endosperm protein content, on the other hand, depends to a greater extent on the environment and agricultural practices.

The objective of the present work was to study the waxy mutant lines of bread wheat and the influence that the environment and the genotype (composition of HMW glutenin subunits) has on some of their quality parameters (sedimentation volume and mixograph parameters) and starch paste viscosity.

\section{Materials and Methods}

\section{Plant materials}

The experimental material included $38.0 \%$ amylose (i.e., waxy) $\mathbf{F}_{6}$ and $\mathbf{F}_{7}$ lines of bread wheat (Triticum aestivum L.) derived from crosses between the cultivar 'Califa' and the 'Waxy Line' triple mutant (100\% amylopectin). This parental 'Waxy Line' was obtained by crossing the cultivar 'Bai Huo', which lacks the waxy protein Wx-D1 (alleles $W x-A l a$, $W x-D I b, W x-B I e$ ) with a Chinese bread wheat variety, which lacks the proteins Wx-Al and $W x-B 1$ (alleles $W x-A I b, W x-D I a, W x-B I b$ ). The waxy line mutants and the parentals were grown in the field in an experimental design with two random complete blocks each, in E.T.S.I. Agrónomos Agricultural Experimental Station, Madrid, Spain, in 2003 and 2004. 


\section{Electrophoretic analysis}

Glutenins were extracted from crushed grain (Singh et al. 1991) and the extracts fractionated by SDS-PAGE electrophoresis (Payne et al. 1980). The 1B/1R translocation was detected by A-PAGE electrophoresis (Lafiandra and Kasarda 1985). Waxy proteins were extracted from the flour, and electrophoresis performed as described by RodriguezQuijano et al. (1998).

DNA extraction was performed according to Saghai-Maroof et al. (1984). PCR to determine the over-expression of $\mathrm{Bx} 7\left(7^{\mathrm{OE}}\right)$ was performed as described in Ragupathy et al. (2008).

\section{Evaluation of quality traits}

Sedimentation volume (SDSS) was measured according to Dick and Quick (1983). Mixograph peak mixing development time [MDT] and resistance to breakdown [BDR] were determined using $10 \mathrm{~g}$ of flour and a National Manufacturing Co. Mixograph (Lincoln, NE), as described by Finney and Shogren (1972). All measurements were replicated twice.

\section{Starch properties}

Starch viscosity was analysed using a Rapid Visco Analyser (RVA-3D, Newport Scientific, Pty. Ltd.). Flour ( $3.5 \mathrm{~g}$ ) was mixed with $24 \pm 0.1 \mathrm{ml}$ of distilled water and $1 \mathrm{ml}$ of $\mathrm{AgNO}_{3}(10 \%)$ (Batey et al. 1997), and the mixture processed using profile standard 1 (Method ICC 162). Peak starch viscosity (PV), trough viscosity (TV), final viscosity (FV) and were then derived in rapid visco units (RVU), and the time to peak viscosity (TP), in min. from the rapid visco analysis curve. From these values were calculated breakdown (BKD, peak minus trough viscosity) and setback (SB, final minus trough viscosity). All measurements were replicated twice.

\section{Statistical analysis}

Statistical analysis was performed using statistical software (Version SAS Institute, 8.2). Analysis of variance (General Linear Model Procedure, F-test on type III sum of squares) was conducted to assess whether siguificant variation existed among genotype protein alleles and environments. The differences between the pairs of alleles were tested using the $t$-test. Linear relationships among all parameters were examined by generating Pearson conrelation coefficients.

\section{Results}

The HMW glutenin subunit compositions of the parental 'Califa' and 'Waxy line' were 1 , $7^{\mathrm{OF}}+8,5+10$ and Null, $7^{*}+9,2+12$, for $G l u-A l$, Ghi-Bl and $G l u-D I$ loci, respectively. 'Califa' showed a 1B/1R translocation but in this study the lines analysed did not have the translocation. Figure 1 shows the over-expression of $\mathrm{Bx} 7\left(7^{\mathrm{OE}}\right)$ glutenin subunit present in 'Califa'. Figure 2 shows the RVA curves for 'Califa' and 'Waxy Line' (parents) and two 
waxy lines (W16 and W149). The HMW glutenin subunits of Glu-B1 locus of 'Califa' ( $7+8 *$ subunits) have been called $a l$ alelle because until now the over-expression has been only described on this allele (Butow et al. 2004).

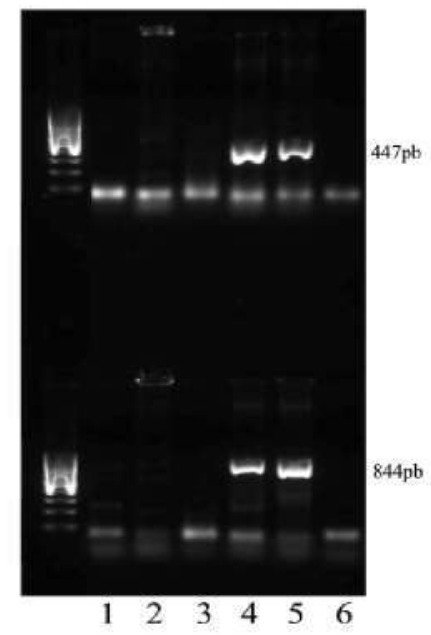

Figure 1. Composition in $\mathrm{Bx} 7^{\mathrm{OE}}$ encoded by $G l u-B 1$ locus: two waxy lines without $\mathrm{Bx} 7^{\mathrm{OE}}$ (slots $1-2$ ), and their parents ('Waxy Line' and 'Califa', slots 3 and 4 , respectively). The varieties controls 'Glenlea' (slot 5) and

'Chinese Spring' (slot 6). Molecular marker is included on the left

\section{Averages and ranges for the parameters measured}

Table I shows data for the sedimentation volume (SDSS), mixograph parameters (MDT and $\mathrm{BDR}$ ) and viscosity parameters (PV, BKD, SB and TP) for the waxy lines $\mathrm{F}_{6}$ and $\mathrm{F}_{7}$, the parent lines and the control varieties. Results of the tests (sedimentation volume, mixograph and starch viscosity) for the waxy lines had indicated that, for the majority of the tests, there is a wide range of values, as seen in Table 1. For sedimentation volume, mixograph values and value of starch peak viscosity (PV) and breakdown (BKD) the

Table 1. Means ( \pm standard deviation) and range for the sedimentation volume (SDSS) and mixograph (MDT and BDR) and viscosity variables (PV, BKD, SB and TP) of waxy lines, 'Califa' and the 'Waxy Line' parents in two years (2003 and 2004) analysed

\begin{tabular}{lcccc}
\hline \multirow{2}{*}{ Quality Test } & \multicolumn{2}{c}{ Waxy Lines } & 'Califa' & 'Waxy Line' \\
\cline { 2 - 5 } & Mean \pm Sd & Range & Mean \pm Sd & Mean \pm Sd \\
\hline SDSS (mm) & $98.6 \pm 10.5$ & $70.0-117.5$ & $101.0 \pm 1.8$ & $87.5 \pm 2.7$ \\
MDT (s) & $162 \pm 5.0$ & $53-290$ & $256 \pm 1.0$ & $82 \pm 2.0$ \\
BDR (\%) & $25.6 \pm 6.7$ & $13.6-46.7$ & $16 \pm 1.2$ & $33 \pm 1.4$ \\
PV (RVU) & $203.7 \pm 34.5$ & $131.9-271.5$ & $137.0 \pm 0.8$ & $195.4 \pm 22.6$ \\
BKD (RVU) & $131.1 \pm 24.3$ & $79.9-178.9$ & $47.5 \pm 0.1$ & $131.8 \pm 2.0$ \\
SB (RVU) & $32.4 \pm 6.1$ & $17.5-42.2$ & $80.8 \pm 0.1$ & $43.9 \pm 3.3$ \\
TP (min) & $3.6 \pm 0.1$ & $3.5-3.8$ & $5.7 \pm 0.1$ & $3.7 \pm 0.1$ \\
\hline
\end{tabular}


ranges indicate that some of the waxy lines have values higher than the parents (Table 1) and that the average peak viscosity of the waxy lines are higher than their parents.

Influence of environment and genotype on the different parameters

Analysis of variance (Table 2) shows that the sedimentation volume in these waxy lines is not influenced by environment but is influenced by the over expression of HMW glutenin subunit $\mathrm{Bx} 7\left(\mathrm{Bx} 7^{\mathrm{OE}}\right)$ controlled by locus $G l u-B 1$. The interactions and field replications are not including in the Table 2 of results because they are not significant. The model only explains $27 \%$ of the variation due to this effect. The sedimentation volume of the waxy lines that carry the $\mathrm{Bx} 7^{\mathrm{OE}}$ is significantly greater than those that do not (Table 3 ).

Table ?. Mean squares from analysis of variance for sedimentation volume (SDSS), viscosity RVA (PV, $\mathrm{BKD}, \mathrm{SB}$ and TP and mixograph parameters (MDT and BDR) of waxy lines F6 and F7

\begin{tabular}{lcccrrr}
\hline Source & df & SDSS & PV & BKD & SB & TP \\
\hline Year & 1 & 238.0 & 2732.2 & 1170.7 & 10.1 & 0.004 \\
Glu- $A 1$ & 1 & 147.5 & 1040.9 & 720.4 & 18.2 & $0.041^{* *}$ \\
Bx7OE & 1 & $545.6^{*}$ & 101.9 & 10.2 & 19.0 & 0.007 \\
Glu-DI & 1 & 46.6 & 165.6 & 16.6 & 8.4 & 0.000 \\
Error & 71 & 84.8 & 1201.8 & 633.0 & 49.43 & 0.000 \\
\hline Source & df & MDT & BDR & & & \\
\hline Year & 1 & $9106.5^{* *}$ & $260.2^{* *}$ & & & \\
Glu- $A I$ & 1 & 2590.8 & 5.5 & & & \\
Bx7 OE & 1 & $25414.2^{* *}$ & 42.1 & & & \\
Glu-DI & 1 & $8150.5 * *$ & $330.8 * *$ & & & \\
Error & 65 & 697.1 & 25.5 & & & \\
\hline
\end{tabular}

** and * significant at $\mathrm{P}<0.01$ and $\mathrm{P}<0.05$, respectively.

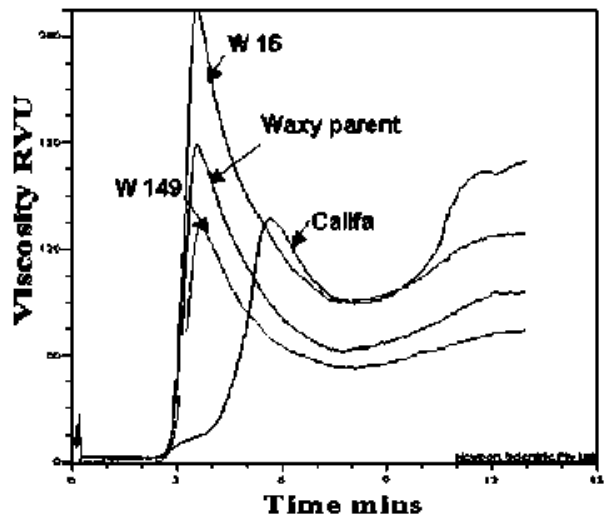

Figure 2. RVA viscosity curves of parents ('Califa' and 'Waxy Line') and two waxy lines, W16 and W149 
Analysis of variance for the starch paste viscosity measurements by RVA indicated that, in the waxy lines, none are influenced by environment (Table 2). Of the parameters that were analyzed, only the TP was influenced by genotype, this being due to variation at $G h-A 1$. The waxy lines with HMW glutenin subunit 1 at the $G l u-A l$ locus showed peak viscosity at an earlier time than those with the null allele (Table 3), even though the model explains only $22 \%$ of the variation.

Table 3. T tests returning signilicant results for sedimentation volume (SDSS), nixograph parameters (MDT and BDR) and tine to peak viscosity (TP) in the waxy lines analysed

\begin{tabular}{|c|c|c|c|c|c|c|c|}
\hline \multirow[t]{2}{*}{ Paraneters } & \multicolumn{3}{|c|}{ Allelic composition conpared } & \multicolumn{2}{|c|}{ Means } & \multirow[t]{2}{*}{$d f$} & \multirow[t]{2}{*}{$T$-test } \\
\hline & $\mathrm{x}$ & & $\mathrm{Y}$ & $\mathrm{X}$ & $\mathbf{Y}$ & & \\
\hline SDSS & $\mathrm{B} \times 7^{\circ \mathrm{E}}+$ & ws & $\mathrm{Bx} 7^{\mathrm{aE}}$ & $104.8 \pm 6.9$ & $94.5 \pm 10.5$ & 74 & $4.7^{* * *}$ \\
\hline MDT & $\mathrm{B} \times 7^{6 \mathrm{E}}+$ & ws & $\mathrm{B} \times 7^{\mathrm{CE}}-$ & $209 \pm 34$ & $138 \pm 38$ & 68 & $11.1^{* *}$ \\
\hline TP & Glu-Al Null & ws & Glu-Al l & $3.62 \pm 0.1$ & $3.56 \pm 0.1$ & 74 & $3.6^{* *}$ \\
\hline MDT & $G / u-D / 5+10$ & $v s$ & Glu-D1 2+12 & $187 \pm 45$ & $118 \pm 22$ & 68 & $7.4^{* * *}$ \\
\hline BDR & G/u-DI $5+10$ & is & Glu-D1 2+12 & $22.6 \pm 5.7$ & $30.9 \pm 4.8$ & 68 & $-6.3^{* * *}$ \\
\hline
\end{tabular}

** Significant at $\mathrm{P}<0.01$.

The mixograph parameters (analysed for 35 , instead of 38 , waxy lines) have an environmental influence (Table 2). For variation of the parameters MDT and BDR, there is an influence of genotype at locus $G l u-D I$ and for the variation of MDT, variation at $G l u-B I$ also has an influence. The model explains $74 \%$ and $46 \%$ of variability (for MDT and BDR respectively) due to environmental and genotypic variation. The waxy lines that carry the $\mathrm{Bx} 7^{\mathrm{OE}}$ or the pair $5+10 \mathrm{HMW}$ glutenin subunits have higher MDT and lower BDR than those that do not have them (Table 3).

Correlations between the quality parameters

The correlations between parameters are shown in Table 4 .

Table 4. Pearson correlation coefficients for the variables analysed in the waxy lines

\begin{tabular}{lllllll}
\hline & SDSS & MDT & BDR & PV & BKD & SB \\
\hline MDT & $0.44^{* * *}$ & - & - & - & - & - \\
BDR & $-0.35^{* *}$ & $-0.45^{* *}$ & - & - & - & - \\
PV & n.s. & n.s. & n.s. & - & - & - \\
BKD & n.s. & n.s. & n.s. & $0.99^{* *}$ & - & - \\
SB & 11.s. & 11.s. & 11.s. & $0.82^{* *}$ & $0.80^{* *}$ & - \\
TP & 11.s. & 11.s. & 11.s. & $-0.49^{* *}$ & $-0.53^{* *}$ & $-0.44^{* *}$ \\
\hline
\end{tabular}

** Significant at $\mathrm{P}<0.01 ;$ ns, not significant

The sedimentation volume conelates positively with MDT and negatively with BDR, both mixograph parameters. There is no significant correlation between sedimentation volume and the different parameters for starch paste viscosity. Among the parameters of 
starch viscosity, there is positive correlation between all of them, except for the time to reach peak (TP) which has a negative correlation with the rest of the parameters for starch viscosity.

\section{Discussion}

The results of this work indicate that the sedimentation volume, the mixograph parameters and the starch paste viscosity have a wide variability in the waxy lines of bread wheat. This variability is due mainly to influence of genotype for sedimentation volume, mixograph time to peak development (MDT) and time to reach peak starch paste viscosity (TP). It was also observed that the various waxy lines had higher values than their parent lines in the case of sedimentation volume, mixograph MDT and some of the starch paste viscosity parameters (PV and TV), which indicates that the waxy lines are transgressive for these parameters. The wide variability indicates that for the majority of the parameters that were analyzed, the behaviour does not differ from that expected for non-waxy lines, except that the time to peak paste viscosity were always less than those for the non-waxy parent line, 'Califa'. The behaviour for TP agrees with that described by other workers who have studied the viscosity for waxy lines of bread wheat (Hayakawa et al. 1997; Fujita et al. 1998; Kiribuchi-Otobe et al. 1997, 1998; Yasui et al. 1997, 1999; Graybosch et al. 2003; Kim et al. 2003).

In non-waxy bread wheat, various authors (Butow et al. 2003, 2004; Radovanovic et al. 2002; Juhász et al. 2003) have described the effect of the presence of over expression of $\mathrm{HMW}-\mathrm{GS} \mathrm{Bx} 7\left(\mathrm{Bx} 7^{\mathrm{OE}}\right)$ at Glu-Bl locus in increasing the sedimentation volume and mixograph parameters. This effect had not been described for waxy lines of bread wheat. The results indicated that the $\mathrm{Bx} 7^{\mathrm{Oe}}$ subunit of the parent line 'Califa' agreed with that reported recently for non-waxy lines of bread wheat. The presence of this glutenin subunit exerts a positive effect on sedimentation volume and mixograph peak development time. In this way, it has a greater effect than that of the HMW glutenin subunits pair $5+10$, which is considered to have the greatest effect on sedimentation volume and mixograph development time (Payne et al. 1980). On the other hand, mixograph breakdown which estimates the dough resistance to over mixing is not influenced by the $\mathrm{Bx} 7^{\mathrm{OE}}$ subunit but influenced by HMW glutenins subunits $5+10$.

These differences that have been observed in the waxy lines in our study due to the genotypic effect of loci $G h-B I$ and $G l u-D l$ do not agree with the results of Graybosch et al. (2003) when they also analysed sedimentation volume and mixographs for waxy lines obtained from different onigins and evaluated in different environments. In their case, the waxy lines had lower values of sedimentation volume and mixograph parameters than the non-waxy controls. These authors questioned whether this behaviour was due to the inherent nature of the waxy lines or if these lines, in particular, had a genotype with lower values for baking quality parameters.

Our results have indicated that the year does not have an effect on any of the parameters analyzed by the RVA for the waxy lines which is in agreement with the results of Graybosch et al. (2003) who analyzed waxy lines at three locations. Viscosity parameters 
for waxy lines were spread over a wide range as reported by Graybosch et al. (2003) and Han et al. (2004), who also found a wide variation in the viscosity of waxy lines of bread wheat and rice respectively. It is interesting to note the wide range found for the peak starch pasting viscosity. This parameter is considered to be of great interest since it is one of the indicators for starch viscosity relevant to end use quality of wheat varieties. When the variety is non-waxy, a greater or lesser peak viscosity has been associated with the ratio of amylose/amylopectin of the endosperm starch (Zeng et al. 1997) and consequently with variation of genes at the $W x$ locus that control amylose synthesis. Thus, the fact that in this study the waxy lines which lack amylose, also showed variation in the peak viscosity, indicates that amylopectin and its genetic control could play an important role in determining the paste viscosity of these lines. In view of this, future work would be needed to measure the variability for those loci involved in the synthesis of amylopectin (loci Sbe) for waxy lines of bread wheat. The correlations detected between different parameters that have been analyzed in waxy lines show that there is no correlation between the parameters that measure baking strength (sedimentation volume and mixograph parameters) and starch paste viscosity.

It can be concluded that, for the waxy lines that were analyzed, the genotype of the variety is involved in quality parameters of the waxy flour. The independence of baking strength and starch viscosity and the effect of genotype on both, could have much application for improvement to obtain lines with different characteristics, permitting selection for different end uses, based on physico-chemical properties

\section{Acknowledgement}

This work was supported by Grant No. AGL 2006-8025 from Comisión Interministerial de Ciencia y Tecnología (CICYT) of Spain.

\section{References}

Batey, L.L., Curtin, B.M., Moore, S.A. 1997. Optimization of Rapid-Visco-Aualyser test conditions for predicting Asian noodle qualicy. Cereal Chem. 74:497-501.

Betge, A.D. Giroux, M.J., Morris, C.F. 2000. Susceptibility of waxy starch granules to mechanical damage. Cereal Chem. 77:750-753.

Butow, B.J., Ma, W., Gale, K.R., Comish, G.G., Rampling, L., Larroque, O., Morell, M.K., Békés, F. 2003. Molecular discrimination of $\mathrm{B} \times 7$ alleles demonstrates that a highly expressed high-molecular-weight glutenin allele has a major impact on wheat flour dough srength. Theor. Appl. Genet. 107:1524-1532.

Butow, B.J., Gale, K.R.. Ikea, J., Juhász, A.. Bed, Z., Tamás, L., Gianibelli, M.C. 2004. Dissemination of the highly expressed $\mathrm{B} \times 7$ glutenins subunit (Gli-BI allele) in wheat as revealed by novel PCR markers and RP-HPLC. Theor. Appl. Genet. 109:1525-1535.

Dick, J.A., Quick, J.S. 1983. A modified screening test for rapid estimation of gluten strength in early generation durum wheat breeding lines. Cereal Chem. 60:315-318.

Echt, C.S., Schwarzz. D. 1981 . Evidence for the inclusion of controlling elements within the structural gene at the waxy locus in maize. Genetics 99:275-284.

Finney, K.F., Shogren, M.D. 1973. A ten-gram mixograph for determining and predicting functional properties of wheats flours. Baker's Digest 46:32-35, 38-42, 77 .

Fujica, S., Yamamoto, H., Sugimoto, Y.. Morita. N., Yam, M. 1998. Thermal and crystalline properies of waxy wheat (Triticum destivtum L.) starch. J. Cereal Sci. 27:1-5. 
Graybosch, R.A., Souza, E., Berzonsky, W., Baenziger, P.S., Chung, O. 2003. Functional properties of waxy llours: Genotypic and environmental effects. J. Cereal Sci. 38:69-76.

Han, Y., Xu, M., Liu, X., Yan, Ch., Korban, S.S., Chen, X., Gu, M. 2004. Genes coding for starches branching enzymes are major contributors to starch viscosity characteristics in waxy rice (Oryza sativa L.). Plant Sci. $166: 357-364$.

Hayakawa, K., Tanaka, K., Nakanura, T., Endo, S., Hoshino, T. 1997, Quality characteristics of waxy hexaploid wheat (Triticum aestivum L.): Properties of starch gelatinization and retrogradation. Cereal Chen. 74:576-580.

Julász, A., Lamoque, O.R., Tannás, L., Hsan, S.L.K., Zeller, F.J., Békés, F., Bedö, Z. 2003. Bánkuti 1201 - an1 old Hungarian wheat variety with special storage protein composition. Theor. Appl. Genet, 107:697-704.

Kim, W., Jolusson, J.W., Graybosch, R.A., Gaines, C.S. 2003. Physicochenical properties and end-use quality of wheat starch as a function of waxy protein alleles. J. Cereal Sci, 37:195-204.

Kinibuchi-Otobe, C., Nagamine, T., Yanagisawa, T., Ohnishi, M., Yannaguchi, I. 1997. Production of hexaploid wheats with waxy endospern character. Cereal Chem. 74:72-74.

Kiribuchi-Otobe, C., Yanagisawa, T., Yanaguchi, I., Yoshida, H. 1998. Wheat mutant with waxy starch slowing stable hot paste viscosity. Cereal Chen. 75:71-672.

Lafiandra, C., Kasarda, D.D. 1985. One and two-dinemsional (two-pH) polyacrylainide gel electrophoresis in a single gel: separation of wheat proteins. Cereal Chem. 62:314-319.

McPlerson, A.E., Jane, J. 1999. Comparison of waxy potato with other root and tuber starches. Carbohydrate Polyners 40:57-70.

Nakanura. T., Yamamori, M., Hirano, H., Hidaka, S. 199?????? Identification of three Wx proteins in wheat (Triticum aestivum L.). Biochem. Genet. 31:75-86.

Nakanura, T., Yamannor, M., Hirano, H., Hidaka, S., Naganine, T. 1995. Production of waxy (anylose-free) wheats. Mol. Gen. Genet. 248:253-259.

Naranjo, T., Roca, A., Goicoecha, P.G., Giraldez, R. 1987. Arm homoeology of wheat and rye chronosones. Genome 29:873-882.

Payne, P.I., Law, C.N., Mudd, E.E. 1980. Control of honnoeologous group 1 chromosones of the highl-molecular-weight subunits, a major protein of wheat endospern. Theor. Appl. Genet. 58:113-120.

Payne, P.I., Corfield, K.G., Blacknnan, A.J. 1979. Identification of a highl-Inolecular-weight subunit of glutenin whose presence correlates with breadınaking quality in wheats of related pedigree. Theor. Appl. Genet. $55: 153-159$

Payne, P.I., Holt, L.M., Worland, A.J., Law, C.N. 1982. Srucnural and genetic studies on the high-molecular-weight subunits of wheat glutenin. Part 3: telocentric mapping of the subunit genes on the long arm of the homoeologous group 1 chromosomes . Theor. Appl. Genet. 63:129-138.

Preiss, J. 199l. Biology and molecular biology of starch synthesis and its regulation. Plant Mol. Cell. Biol. 7:59-114.

Radovanovic, N., Cloutier, S., Brown, D., Humplreys, D.G., Lukow, O.M. 2002. Genetic variance for gluten strength contributed by high molecular weight glutenins proteins. Cereal Chem. 79:843-849.

Ragupathy, R., Naeem, H.A., Reimer, E., Lukow, O.M., Sapirstein, H.D., Cloutier, S. 2008. Evolutionary origin of the seginental duplication encompassing the wheat GLU-BI locus encoding the overexpressed $\mathrm{Bx} 7$ $\left(\mathrm{B} \times 7^{\mathrm{OE}}\right)$ high molecular weight glutenin subunit. Theor. Appl. Genet. 116:283-396.

Rodriguez-Quijano, M. Nieto-Taladriz, M.T. Carrillo, J.M. 1998. Polymorphism of waxy proteins in Iberian hexaploid wheats. Plant Breed. 117:341-344.

Sasaki, T., Yasui, T., Matsuki, J. 2000. Effect of amylose content on gelatinization, retrogradation and pasting properies of starches from waxy and nonwaxy wheat and their $F_{1}$ seeds. Cereal Chem. 77:58-63.

Saghai-Maroof, M., Soliman, K.M., Jorgensen, R.A. Allard, R.W. 1984. Rjbosomal DNA spacer-length polymorphisins in barley: Mendelian inheritance, chromosomal location, and population dynemics. Proc. Nat. Academy of Sci. USA 81:8014-8018.

Shewry, P.R., Halford, N.G., Tathain, A.S. 1992. High-molecular-weight subunits of wheat glutenin. Plant Mol. Cell. Biology 15: 105-120.

Singh, N.K., Shepherd, K.W. Cornish, G.B. 1991. A simplified SDS-PAGE procedure for separating LMW subwits of glutenin J. Cereal Sci. 14:203-208.

Song. Y., Jane, J. 2000. Characterization of barley starches of waxy, normal and high amylose varieties. Carbohydrate Polymers 41:365-377. 
Yasui, T., Sasaki, T., Matsuki, J. 1999. Milling and flour pasting properties of waxy endospern unutant lines of bread wheat (Trificum aestivum L.). J. Sci.Food Agr. 79:687-692.

Yasui, T., Sasaki, T., Matsuki, J., Yanamori, M. 1997. Waxy endospern mutants of bread wheat (Triticum aestivum L.) and their starch properties. 1997. Breeding Science 47:161-163.

Yoo, S.G., Jane, J. 2002. Structural and physical characteristics of waxy and other wheat starches. Carbohydrate Polyners 49:297-305.

Zell, M., Morris, C.F., Batey, I.L., Wrigley C.W. 1997. Sources of variation for starch gelatinization, pasting, and gelation properties in wheat. Cereal Chen. 74:3-71. 